IRA-International Journal of Technology \& Engineering ISSN 2455-4480

Proceedings of the

International Conference on Science \& Engineering for Sustainable Development (2017)

Pg. no.171-180

Published by: Institute of Research Advances https://research-advances.org/index.php/IRAJTE

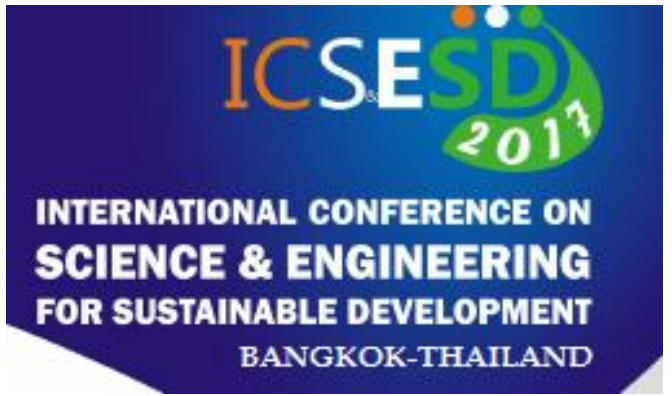

\title{
A Feasibility Study of Supersonic Air Flow for Cooling Application
}

\author{
P.R.Chavan* ${ }^{1}$, Ummid I. Shaikh ${ }^{2}$ \\ ${ }^{1}$ Pimpri Chinchwad College of Engineering and Research, Ravet, Pune (MS),Inida \\ (primechaol@gmail.com) \\ ${ }^{2}$ Pimpri Chinchwad College of Engineering, Nigdi, Pune (MS),Inida \\ (ummid.shaikh@pccoepune.org)
}

Type of Review: Originality Check \& Peer Review under the responsibility of the Scientific Committee of the Conference and The Institution of Engineers (India). DOI: http://dx.doi.org/10.21013/jte.ICSESD201717

\section{How to cite this paper:}

Chavan, P., Shaikh, U. (2017). A Feasibility Study of Supersonic Air Flow for Cooling Application. Proceedings of the International Conference on Science \& Engineering for Sustainable Development (2017), 171-180. doi: http://dx.doi.org/10.21013/ite.ICSESD201717

(C) International Conference on Science \& Engineering for Sustainable Development\& The Institution of Engineers (India).

\section{(cc) BY-NC}

This work is licensed under a Creative Commons Attribution-Non Commercial 4.0 International License subject to proper citation to the publication source of the work.

Disclaimer: The conference papers as published by the Institute of Research Advances (IRA) are the views and opinions of their respective authors and are not the views or opinions of the IRA. The IRA disclaims of any harm or loss caused due to the published content to any party. 


\section{ABSTRACT}

The theoretical study of steady, one-dimensional, isentropic, compressible fluid flow suggests that a convergent-divergent passage is required for accelerating a compressible fluid to supersonic velocities. It also reveals that along with pressure, temperature of the compressible fluid continuously decreases along the flow passage. Air is also a compressible fluid which is freely and abundantly available.

Keeping these facts in mind the possibility of obtaining supersonic flow with the help of compressed air is first studied theoretically. A convergent divergent nozzle is designed and developed for obtaining supersonic flow of air. An experiment is carried out for various back pressures for verifying supersonic flow and measuring the exit temperature of air.

It is observed that supersonic flow can be obtained with minimum back pressure of 1 bar. Exit temperature of air can be varied by changing the back pressure of the nozzle. Temperature drop of air as high as $18.23{ }^{\circ} \mathrm{C}$ could be obtained. These factors prove the potential of supersonic air jet as a good and environmentally friendly cooling medium especially for localized cooling applications.

Keywords: supersonic air jet cooling, tool cooling, supersonic nozzle

\section{Introduction}

It is a well-established fact that convergent-divergent passage is required for accelerating a compressible fluid to a velocity greater than velocity of sound (i.e. Mach Number>1)[1,2]. As the pressure through convergent-divergent passage continuously reduces the temperature of the compressible fluid also continuously decreases. The low temperature air at the nozzle exit may be utilised for cooling applications. One of the potential applications is tool cooling. Conventionally mineral oil based coolant have been used for tool cooling. However the environmental awareness is leading to the critical consideration of conventional cooling lubricants. Andrea Bareggiet. al. [4] have investigated the use of supersonic air jets as alternative to mineral oil coolant and found that supersonic air jets leads to reduced temperature in cutting zone, reduced cutting force and modified chip shape. YogieRinaldyGintinget. al. $[5,6]$ investigated the methods of generating cold air for machining and also studied the environmental concerns about conventional machining.

The focus of the research presented in this paper is to get the answers of the questions: whether it is possible to obtain supersonic flow with the help of compressed air, what could be the minimum back pressure with which supersonic air flow could be obtained, what could be the maximum temperature drop that could be obtained with the minimum back pressure.

For this purpose, first theoretical analysis of steady, one-dimensional, isentropic, compressible air flow through convergent divergent nozzle is done in which variation of temperature, pressure and velocity is studied along the flow with different back pressure.

Then a convergent divergent nozzle is designed and developed for obtaining supersonic flow of air. Experimentation is carried out for various back pressures for verifying supersonic flow and measuring the exit temperature of air. Results are analysed for studying cooling potential of the exit air.

\section{Steady, One-Dimensional Compressible Flow}

Flow in which variation in density is negligible is termed as incompressible; when density variation within a flow is not negligible, the flow is called compressible [3]. The compressibility of flow can also 
be related to Mach number which is the ratio of the flow speed V, to the local speed of sound, $\mathrm{C}$, in the fluid $(\mathrm{M}=\mathrm{V} / \mathrm{C})$. For $\mathrm{M}<0.3$ the maximum density variation is less than $5 \%$. Thus fluid flows with $\mathrm{M}<0.3$ can be treated as incompressible [1,3]. Mach number is an important non-dimensional number which appears in the property relations of compressible flow. It also provides criteria to identify whether the flow is supersonic, subsonic or sonic ( $\mathrm{M}>1$ :supersonic, $\mathrm{M}=1$ :sonic, $\mathrm{M}<1$ subsonic).

By applying continuity equation, $1^{\text {st }}$ law of thermodynamics (Steady Flow energy equation) and second law ( $2^{\text {nd }} \mathrm{T}$-ds equation) to a steady, one dimensional, compressible, isentropic flow of air and treating air as an ideal gas, and neglecting potential energy changes we get,

$$
\frac{d A}{d V}=-\frac{A}{V}\left(1-M^{2}\right)
$$

Where, $\mathrm{A}=$ Area of passage/duct, $\mathrm{V}=$ Velocity of flow and $\mathrm{M}=$ Mach number.

This equation governs the shape of the duct required to accelerate the flow of air to supersonic level. For subsonic flow $(\mathrm{M}<1), \frac{d A}{d V}$ is negative indicating that converging passage is required for accelerating a fluid at subsonic velocities. However, the highest velocity we can achieve by a converging duct is the sonic velocity $(\mathrm{M}=1)$ for which $\frac{d A}{d V}=0$. For supersonic flow $(\mathrm{M}>1), \frac{d A}{d V}$ is positive, which means that diverging passage is required to accelerate a fluid at supersonic velocities. Hence a converging-diverging duct is required for accelerating fluid to supersonic velocities [1,3]. The study of one dimensional adiabatic compressible flow in a constant-area duct with friction reveals that for an initially subsonic flow, the effect of friction is to increase the Mach number towards unity [3]. Utilizing this fact a constant area portion can be attached to the convergent part and it can be insured that sonic flow $(M=1)$ is present at the entry of the divergent part. Hence the duct required for accelerating fluid flow to supersonic velocities will consists of a converging part followed by a constant area part (Straight) followed by a diverging part as shown in fig 1.

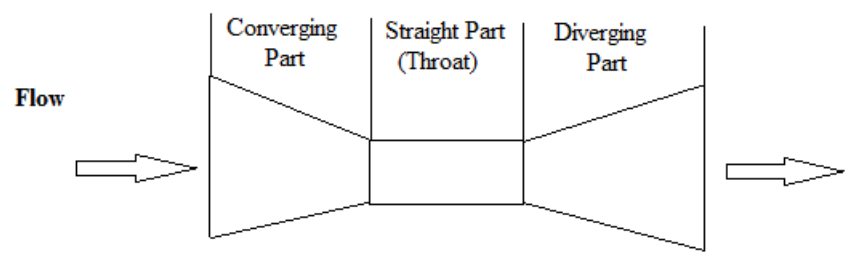

Fig.1 Proposed shape of duct/nozzle for obtaining supersonic flow

\section{Property Variation of Air Flow through a Converging-Diverging Nozzle}

An expression for sonic velocity (C) in ideal gas can be obtained by applying mass balance, energy balance and $2^{\text {nd }}$ law to a sound wave front, as

$$
C=\sqrt{\gamma R T}
$$

Where, $\gamma=$ ratio of specific heat, $\mathrm{R}=$ characteristic gas constant and $\mathrm{T}=$ Absolute temperature of given ideal gas.

A relation for variation of flow area (A) through the nozzle relative to throat area $\left(\mathrm{A}^{*}\right)$ can be obtained from continuity equation, ideal gas equation, isentropic property relations for ideal gas and definition of Mach number, as

$$
\frac{A}{A^{*}}=\frac{1}{M}\left[\left(\frac{2}{\gamma+1}\right)\left(1+\frac{\gamma-1}{2} M^{2}\right)^{\frac{\gamma+1}{2(\gamma-1)}}\right]
$$




$$
\text { Where, } \mathrm{M}=\frac{V}{C}
$$

The property relation for isentropic flow of an ideal gas are also considered,

And

$$
T_{0}=T+\frac{V^{2}}{2 C_{p}}
$$

$$
\frac{T}{T_{0}}=\left(\frac{P}{P_{0}}\right)^{\left(\frac{\gamma-1}{\gamma}\right)}
$$

Here $\mathrm{T}_{0} \& \mathrm{P}_{0}$ are stagnation temperature and pressure at the inlet of the nozzle and $\mathrm{P} \& \mathrm{~T}$ are pressure $\&$ temperature at given location inside the nozzle.

Air is consider as ideal gas with constant properties like $\gamma=1.4, \mathrm{C}_{\mathrm{p}}=1.005 \mathrm{KJ} / \mathrm{KgK}, \mathrm{R}=0.287 \mathrm{KJ} / \mathrm{KgK}$ with property relation

Where $\rho=$ densityofair $\left(\mathrm{Kg} / \mathrm{m}^{3}\right)$

$$
\rho=\frac{P}{R T}
$$

Stagnation pressure $\&$ temperature are considered to be $100 \mathrm{KPa}$ and $300 \mathrm{~K}$ respectively.

Equation no.(2) to (7) are solved simultaneously by using Engineering equation solver software (EES). The results of parametric study are depicted in fig no. (2) to (4).

Fig.2 shows the area variation along flow.

Fig. 3 shows variation of velocity along flow. It is seen that velocity of around $600 \mathrm{~m} / \mathrm{s}$ is present at exit of nozzle.

Fig. 4 shows that temperature of air at the nozzle exit can be as low as 130K. (143K below inlet temperature of air)

From these results it may be concluded that with 1 bar stagnation pressure it may be possible to obtain supersonic flow. Result from fig. 3 compelled the authors to study the feasibility of using supersonic air for various cooling application. 


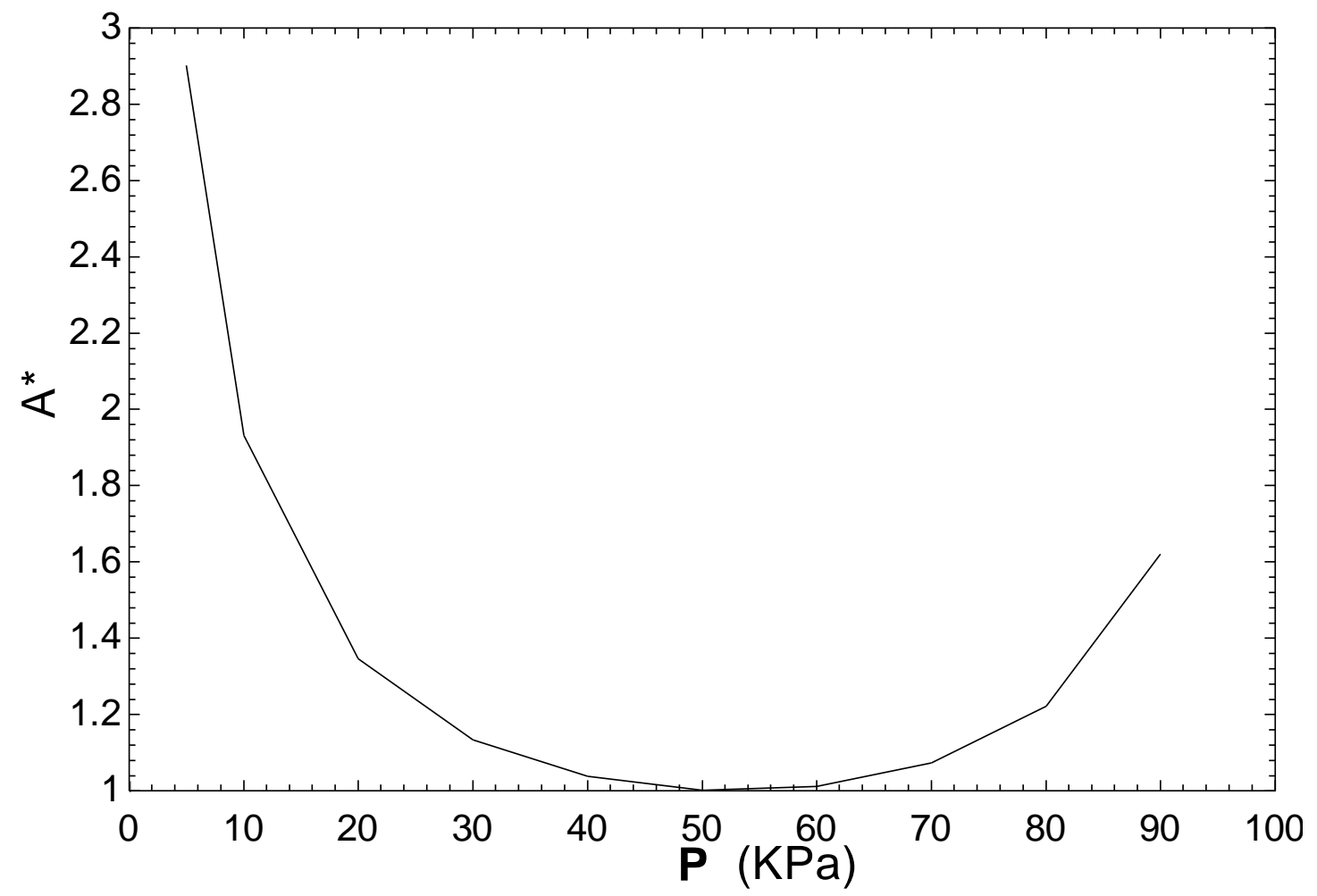

Fig.2 Area variation along flow

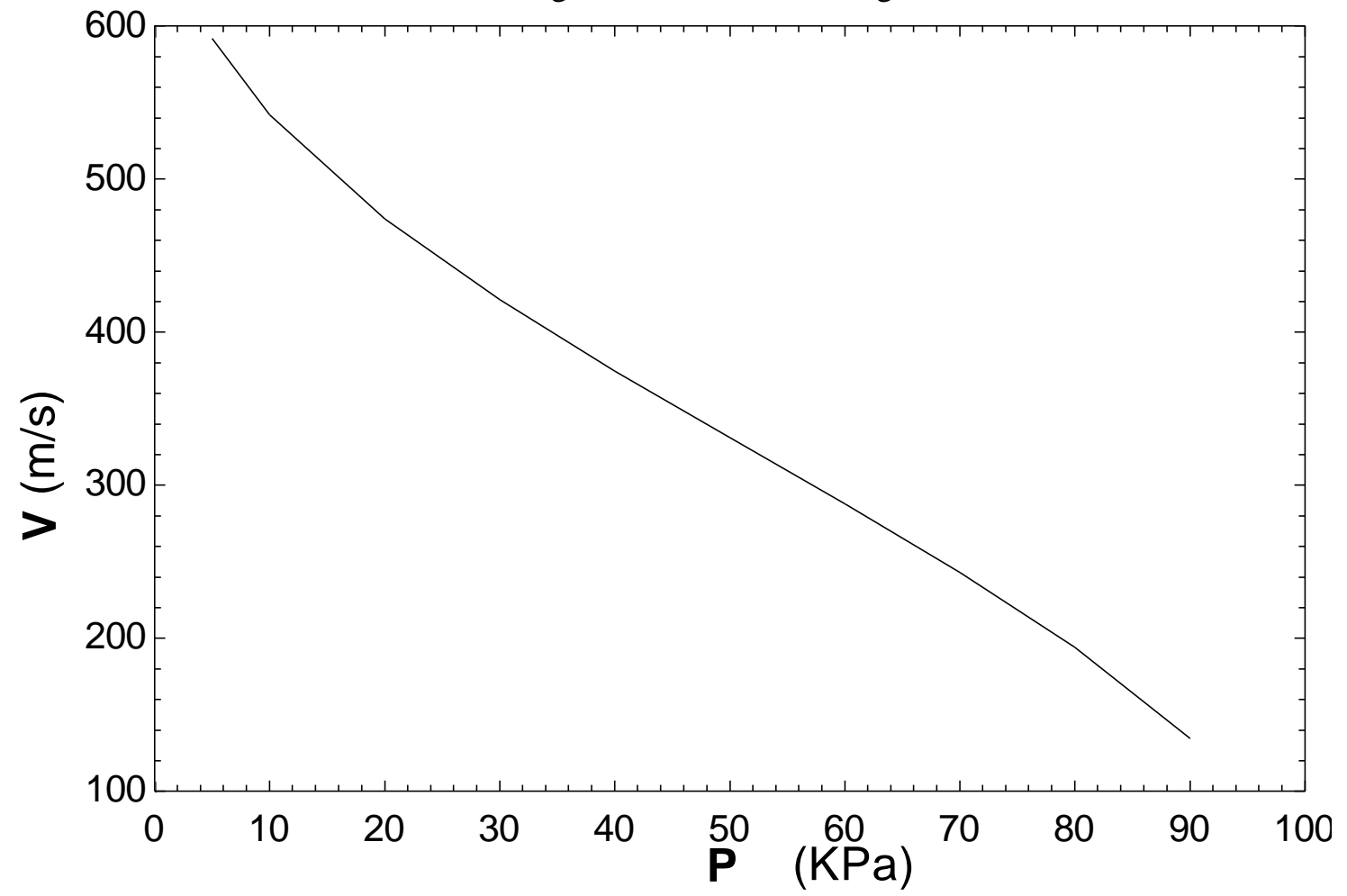

Fig.3Variation of velocity along flow 


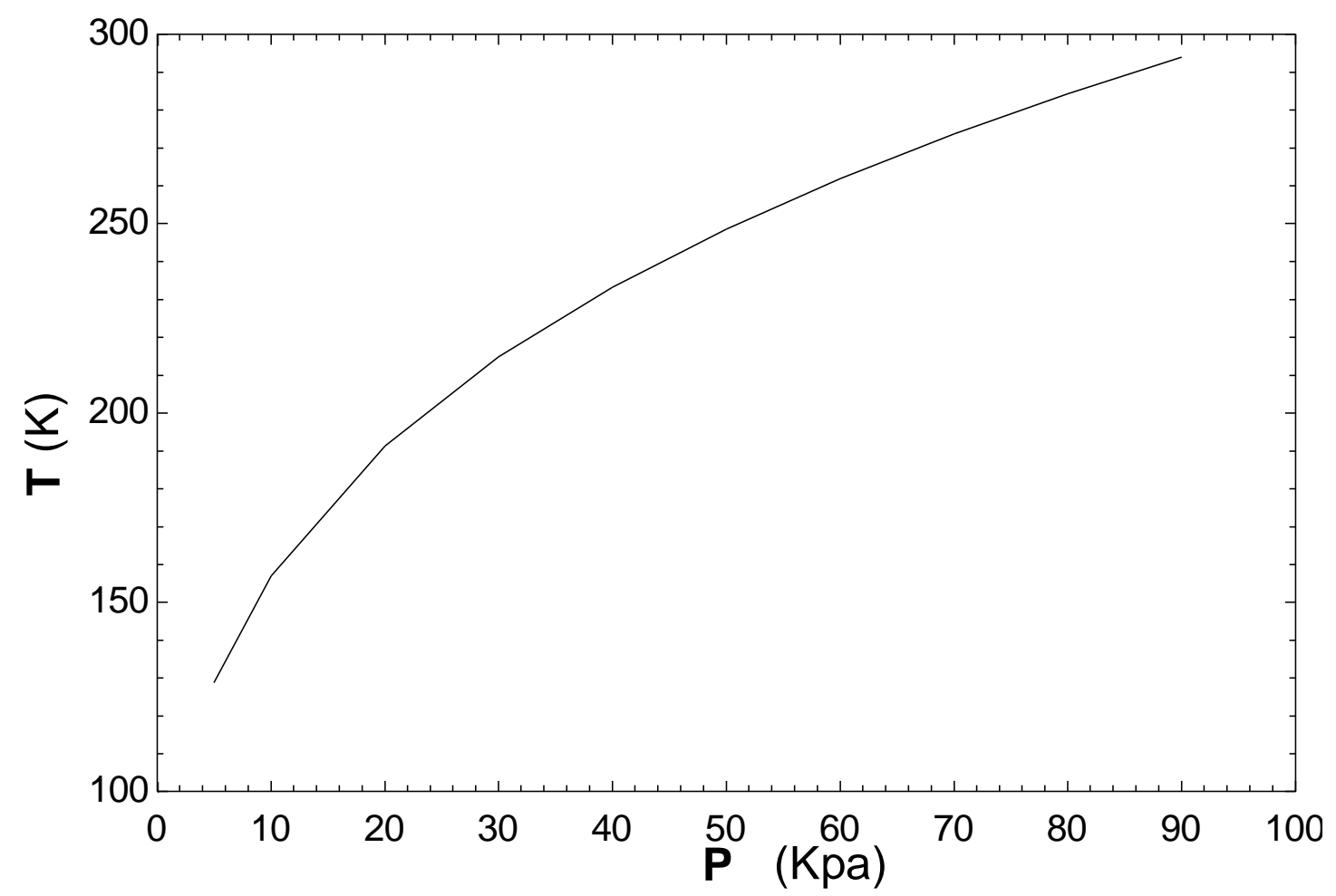

Fig.4 Variation of Temperature along flow

Level-two heads

\section{Design of Supersonic Air Nozzle}

In order to practically verify whether it is possible to obtain supersonic air flow with $100 \mathrm{KPa}$ stagnation pressure and to have an idea about the actual exit temperature of air a supersonic air nozzle is designed and manufactured.

Although Fig.1 reveals contoured convergent divergent passage, for short nozzle it is not necessary to have contoured flow passage[3].

Following methodology is used to design the nozzle

1.Exit Mach no. $\left(\mathrm{M}_{2}\right)$ is determined by previous theoretical analysis

2.ThePrandtl-Mayer function is determined for $\mathrm{M}_{2}$ [3].

$$
v(M)=\sqrt{\frac{\gamma+1}{\gamma-1}} \tan ^{-1} \sqrt{\frac{\gamma-1}{\gamma+1}\left(M^{2}-1\right)}-\tan ^{-1} \sqrt{M^{2}-1}
$$

3. Maximum Expansion Angle is determined [3].

$$
\emptyset_{\max }=\frac{v\left(M_{2}\right)}{2}
$$

4.Throat diameter $\left(D^{*}\right)$ is selected to be $14 \mathrm{~mm}$ as per manufacturing feasibility and throat area (A*) is calculated.

5. Inlet and Exit diameter (D1\&D2) of the nozzle are calculated with the help of theoretical analysis presented in section 3 .

6. Length of convergent portion (L1), throat ( $\left.\mathrm{L}^{*}\right)$ and divergent portion (L2) are selected appropriately.

7. Actual expansion angle is calculated from the geometry by the formula 


$$
\emptyset_{2}=\tan ^{-1}\left[\frac{D_{2}-D^{*}}{2 L_{2}}\right]
$$

8. In order to avoid normal shocks in the nozzle $\emptyset_{2}$ must be less than $\emptyset_{\max }$ [3]. Considering these facts $\mathrm{D}^{*}, D_{2}$ and $\mathrm{L}_{2}$ are finalized as $\mathrm{D}^{*}=14 \mathrm{~mm}, D_{2}=26 \mathrm{~mm}$ and $\mathrm{L}_{2}=60 \mathrm{~mm}$.

Manufacturing feasibility and dimensions of standard pipe fittings viz. sockets, unions, valves etc. are also considered while deciding the dimensions of the nozzle.

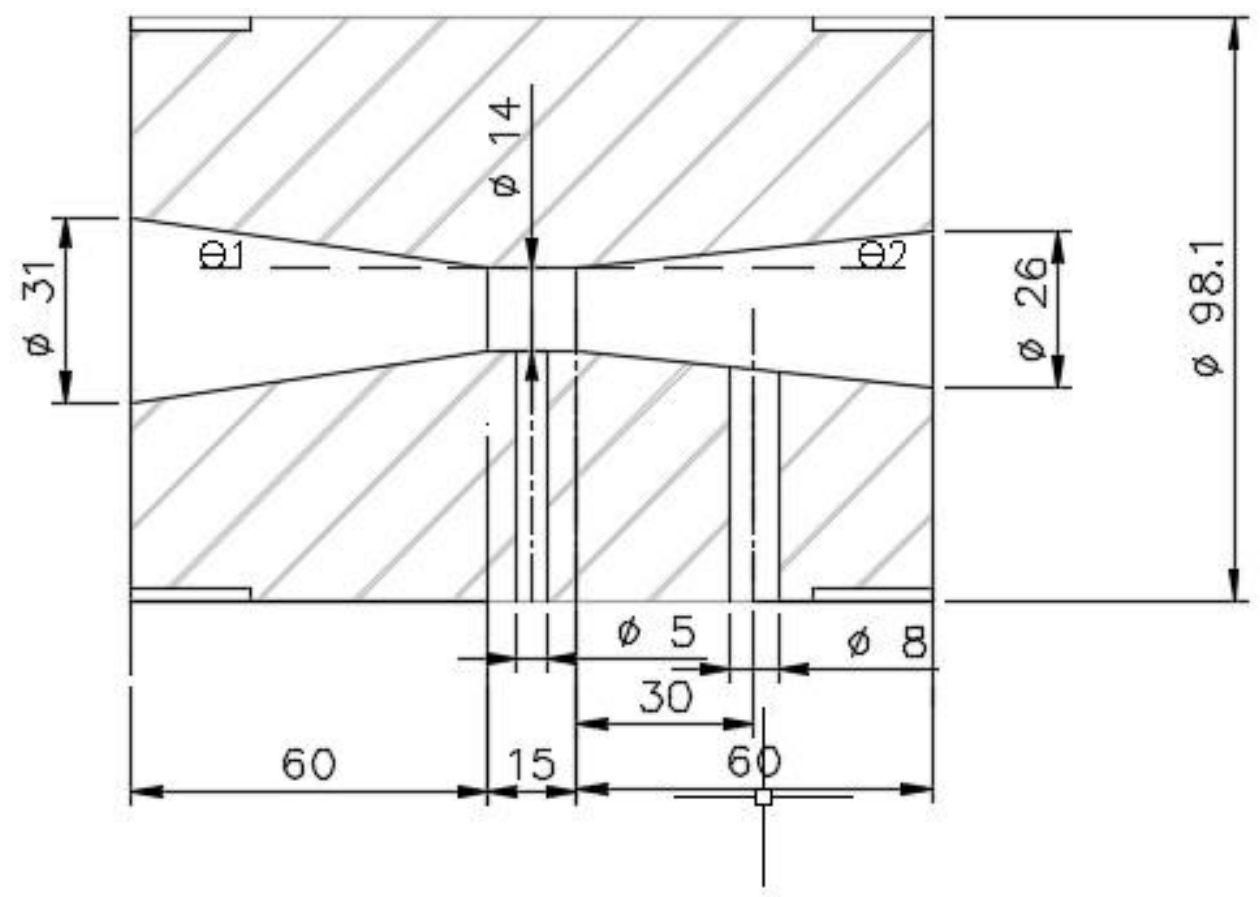

Fig.5 Final Drawing of Nozzle

\section{Manufacturing of Nozzle}

The nozzle is manufactured from a $38.1 \mathrm{~mm}$ diameter M.S. rod on a manual lathe machine. Two holes of diameter $5 \mathrm{~mm}$ are drilled for fitting manometer as shown in fig 5. External threading is done on both ends as shown for fitment of sockets and stop valve.

\section{Experimentation}

The experimental set-up is as shown in fig 6. Two stage reciprocating air compressor is used to provide compressed air for the experimentation. And auxiliary tank is connected to the receiver tank of compressor through valve. The convergent-divergent nozzle is attached to the auxiliary tank with the help of connector and socket. Stop valve 2 is fitted to the other end of the nozzle by a connector and socket. Ktype thermocouple with digital temperature indicatoris used to measure the temperature of air at nozzle exit. Differential U-tube water manometer is used to observe the pressure difference between the throat and divergent section of the nozzle. Two pressure gauges are used to measure air pressure in receiver and auxiliary tank. Air is compressed up to 5barg and stored in the receiver tank with both valve closed. Then valve-1 is opened until pressure in the auxiliary tank reaches 4barg (equal to required stagnation pressure) 
and then valve-1 is closed. Valve-2 is suddenly opened and temperature and manometer pressure difference is noted. Three readings of temperature at inlet and outlet were taken and average is calculated. The procedure was repeated for $3 \mathrm{barg}$, $2 \mathrm{barg}, 1 \mathrm{barg}$, and $0.5 \mathrm{barg}$ pressures in the auxiliary tank.

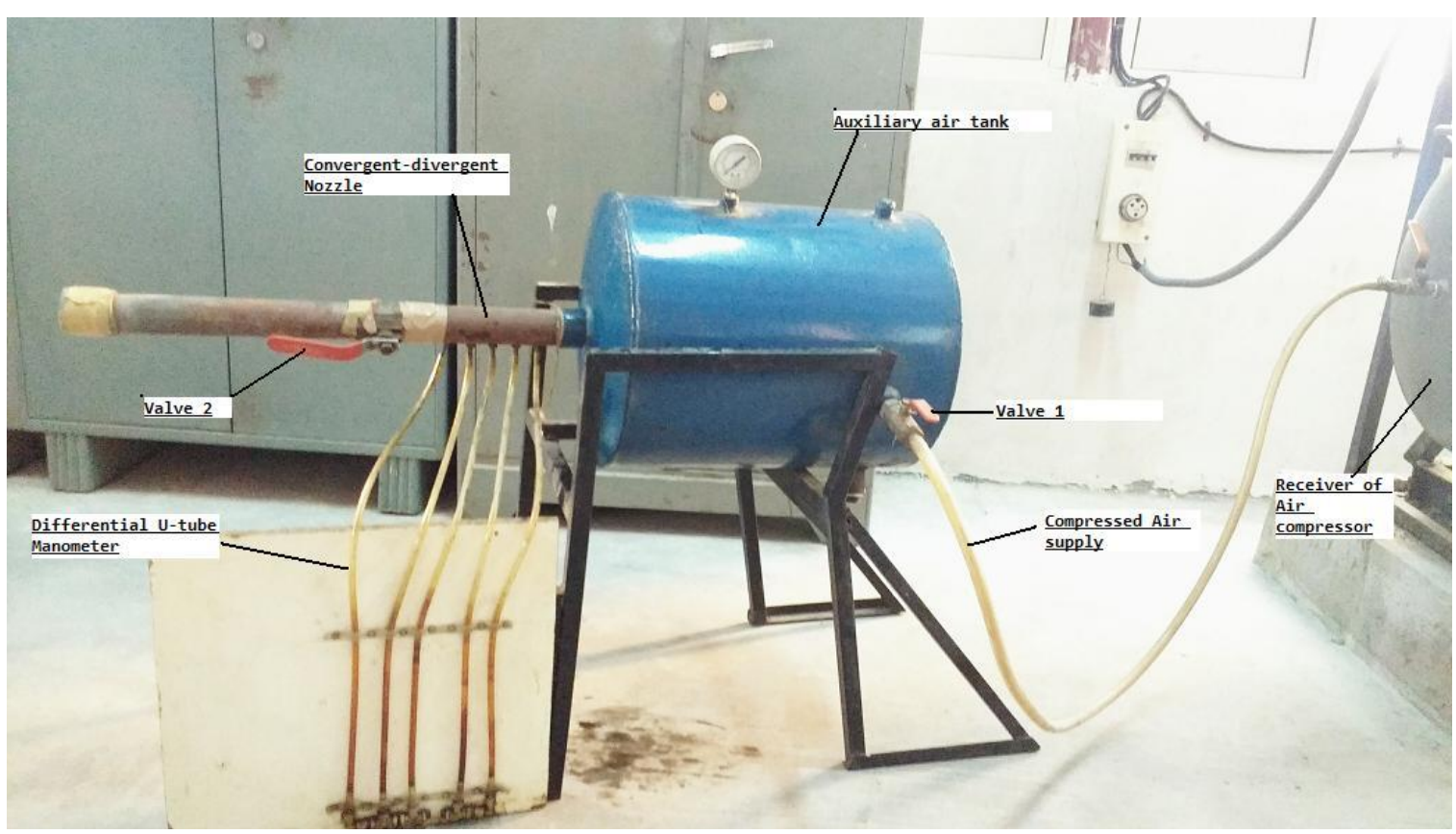

Fig.6 The experimental set-up

\section{Results and Discussion}

For back pressures 4 barg, 3barg, 2barg and 1 barg it is observed that when the valve 2 is opened, manometer showed decrease in pressure throughout the length of the nozzle i.e. from convergent section to divergent section. This is the indication of supersonic flow in divergent section [1,2]. However for 0.5 barg back pressure when the valve 2 is opened, manometer showed decrease in pressure of convergent section and increase in pressure to divergent section. This is the indication of subsonic flow in the nozzle $[1,2]$. Hence it is experimentally verified that supersonic flow can be obtained with minimum back pressure of 1 bar with compressed air. 


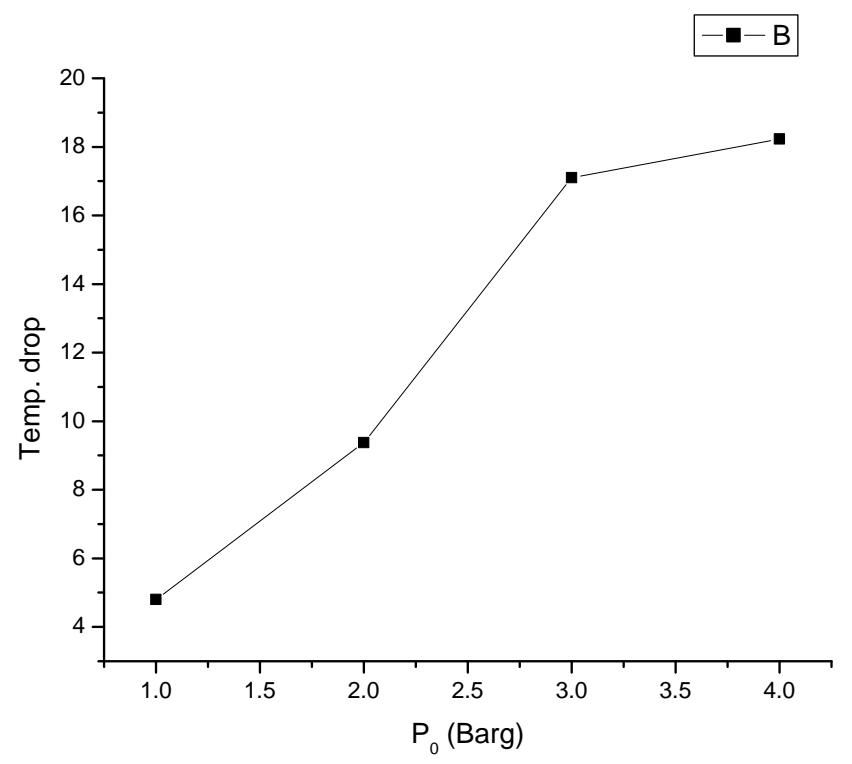

Fig.7 Temperature Drop of air for various back pressures.

It is also observed that the temperature drop of air from inlet to outlet of the nozzle increases with back pressure as shown in fig. 7. The minimum temperature drop of $4.8{ }^{\circ} \mathrm{C}$ is observed at 1 barg back pressure and maximum temperature drop of $18.23^{\circ} \mathrm{C}$ is observed at 4 barg back pressure. The minimum temperature of air at the exit of the nozzle was noted to be $16.8{ }^{0} \mathrm{C}$ at 4 barg back pressure when the inlet temperature is $36.3^{\circ} \mathrm{C}$.

\section{Conclusion}

From this research it can be concluded that supersonic flow can be obtained with minimum back pressure of 1 barg. The exit air temperature decreases with increase in back pressure.

Supersonic air jet has a very good potential for localized cooling applications like tool cooling because of the following reasons:

Considerable temperature drop could be obtained with supersonic air flow. It also provides the flexibility of varying exit air temperature by changing the back pressure of the nozzle. Air is freely and abundantly available without any harmful effects on environment. The supersonic exit velocity of air at nozzle outlet (Ma>1) can increase the heat transfer coefficient between air and hot surface which is otherwise on the lower side.

\section{References}

[1] Robert W. Fox, Alan T. McDonald, Introduction to fluid Mechanics, $5^{\text {th }}$ edition, John Wiley \& Sons Inc.

[2] Yunus A Cengel, Michael A Boles, Thermodynamics an Engineering Approach, $6^{\text {th }}$ Edition, 2008, Tata McGraw Hill Company Inc. New York.

[3] John D. Anderson Jr., Modern Compressible flow, $2^{\text {nd }}$ Edition, McGraw Hill Publishing Company.

[4] Andrea Bareggi, Andrew Torrance, Garret O’Donnell, Advances in Manufacturing Technology, 2006, pp 261-266. 
[5] Yogie Rinaldy Ginting, Brian Boswell, Wahidul K. Biswas, Mohammad Nazrul Islam, Environmental Generation of Cold Air for Machining, 13th Global Conference on Sustainable Manufacturing - Decoupling Growth from Resource Use, Procedia CIRP 40 (2016) 648 - 652.

[6] Yogie Rinaldy Gintinga, Brian Boswella, Wahidul Biswasb and Nazrul Islama, Advancing Environmentally Conscious Machining, $12^{\text {th }}$ Global Conference on Sustainable Manufacturing, Procedia CIRP 26 (2015) 391 - 396. 